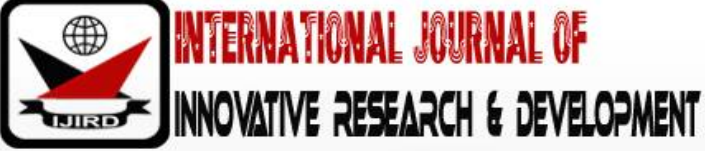

ISSN 2278 - 0211 (Online)

\section{Perceptions of Local Government Leaders on Appreciative Inquiry Approach towards Human Resource Capacity Building: A Case of Zanzilbar Islands' Local Government}

\begin{tabular}{c} 
Rukkaya W. Muhammed \\
Ph.D. Candidate, Open University of Tanzania, Dar es Salaam, Tanzania \\
Haroonah Nsubuga \\
Senior Lecturer, Zanzibar University, Tanzania \\
Omar F. Hamad \\
Associate Professor, Zanzibar University, Tanzania \\
\hline
\end{tabular}

\begin{abstract}
:
This paper explores the perceptions of local government leaders towards appreciative inquiry approach as innovative capacity building at local government context. Thematic qualitative approach was used to collect, analyze and interpret the findings of this study. Fifteen participants from seven selected local government councils in Unguja and Pemba were purposively selected for in-depth interview. Nine themes were observed during data analysis whose results showed that Appreciative Inquiry significantly influences employee's capacity which in general improve firm performance. The study recommended is that, building a firm's human resource capacity is an effective strategy for improving firm performance. Organizations should strive at increasing their human resource capacity because it can lead to superior organizational outcomes. The human resource professionals can help their respective Organizations in achieving this by embracing intensive AI training programs aimed at imparting human resource capacity.
\end{abstract}

Keywords: Appreciative inquiry, human resource, capacity building

\section{Introduction}

Appreciative Inquiry has emerged as a significant approach to fostering organizational change. Ever since its original conception in 1980s, it has gained increasing popularity and is now being used widely to foster change in organisations and communities (Calabrese, 2015, Whitney and Trosten-Bloom, 2003, ICMA, 2011). AI has also inspired an ever-increasing number of academic research publications (Neumann, 2009; Stellnberger, 2010; ICMA, 2011).

However, many aspects of how AI enhances human resource capacity at local government context remains unexplored (Chapagain, 2008; Bushe, 2011; Day and Holladay 2012 and Shawn, 2012). Considering the claim made by AI practitioners and the existence of only few published AIA studies in local government context, this research was designed to address this gap and contributed to the literature on AI studies. Furthermore, the academic literature on AI appears to be fairly quiet in reflecting on AI's weaknesses and deficiencies (Messerschmidt, 2008, Shawn, 2012) as well as tending to point out just the things that work (Bushe, 2007). This is likely due to AI's exclusive focus on positives. Thus, this research aimed at addressing this gap by identifying the shortcomings and difficulties in applying AI in organizational settings with a twist to local government authorities.

It is also reported that, most of the published academic researches on Appreciative Inquiry have been carried out in North America by North American researchers (Stellnberger, 2010; Couch, 2017). Interestingly, AI seems to have little visibility outside of the USA and Canada (Neumann, 2009; Guevara, 2016). This is certainly true in Africa. Few cases have been published in Africa. This study addresses this gap by introducing the innovative AI idea in Zanzibar's Local Government context. The aim of this paper is to explore the perception of Local Government staff on the effectiveness of Appreciative Inquiry towards human resource capacity building at local government authorities in Zanzibar.

\section{Literature Review : Appreciative Inquiry Studies}

Appreciative Inquiry, as a method of research, a process, and a philosophy, has been written about for 25 years (Buchanan, 2014). However, most of the articles have been written within the last ten years. Literature in general espousing AI is fairly abundant (Lahman, 2011; Lehner and Ruona, 2014). Actual studies of AI are fairly sparse as illustrated in Figure 1. Although the focus of this study is on AI's potential in capacity building, consulting AI literature from other fields was useful. Figure 1 shows the distribution of research articles/ thesis that were consulted from various fields to inform this study. Out of 54 articles, 20 articles (32\%) from private sector, twenty-two articles (35\%) from educational sector, eight articles (13\%) were from health sector, four articles from Non-governmental organizations (6\%) 
one from airlines, three articles from information technology, two articles from community level, two articles from media sector and two articles from library institution.

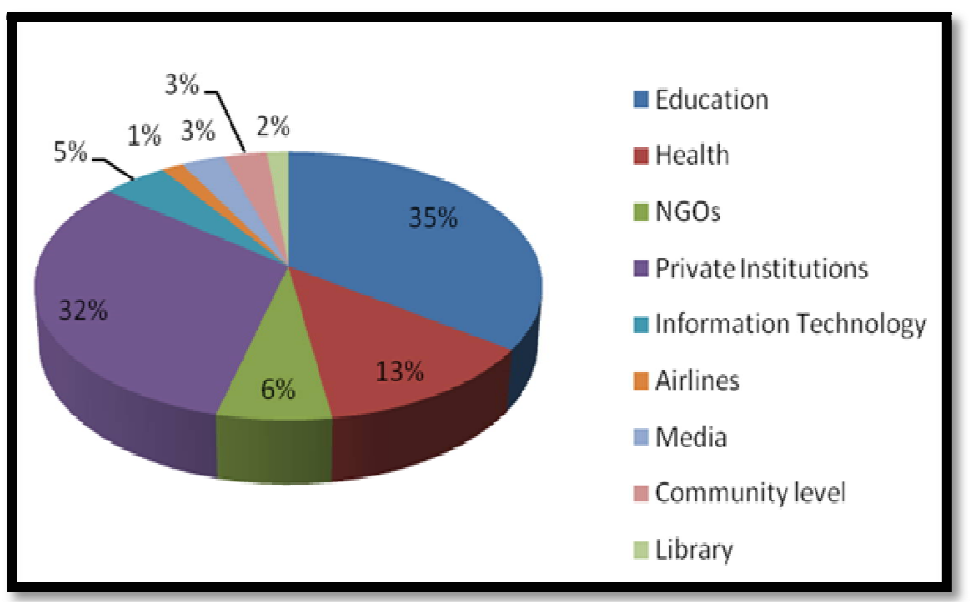

Figure 1: Summary of Distribution of AI Studies from Various Fields

Furthermore, most of the literature reviewed were describes its origin, the process, the assumptions and principles and in some articles, narratives of AI experiences are shared. The Table 1 illustrates what types of writing is being done on the topic of AI for the last ten years.

\begin{tabular}{|c|c|c|c|}
\hline S/ N & Type of AI Studies & Quantity & Percentage \\
\hline 1. & Qualitative studies & 22 & 40.3 \\
\hline 2. & Description of AI & 13 & 23 \\
\hline 3. & Quantitative studies & 07 & 13.4 \\
\hline 4. & Mixed Methods studies & 05 & 9.6 \\
\hline 5. & Proposal/ Conceptual & 03 & 5.7 \\
\hline 6. & Paper Reviews & 03 & 5.7 \\
\hline 7. & Meta-Analysis & 01 & 1.9 \\
\hline & Total Reviewed & 54 & 100 \\
\hline
\end{tabular}

Table 1: Summary of Types of Literature on Appreciative Inquiry Source: Researcher (2017)

Some of the existing literature focused on explaining and reviewing Appreciative Inquiry (Howard, 2013; Lehner and Hight, 2006; Cram, 2010). Other studies explained how the Appreciative Inquiry process was used in a single event in which data was not collected (Calabrese, 2006; Bechtold, 2011). Further more appreciative inquiry has been used as a data collection tools (Baker et al., 2008; Calabrese and Hester, 2010). Appreciative Inquiry has been used as a method for organizational change documented in several case studies (Stellnberger, 2010; Schooley, 2008; Sekerkal et al., 2009; Schooley, 2012; Sarelsky, 2013 and Heiser, 2015) and in transformational learning (Hart et.al, 2008; Carter, 2009; Ratanaphunsri, 2014 and Couch, 2017). Several researchers also concluded that, there is a need for further analytical evaluation of the intersection of the theory and practice of Appreciative Inquiry (Willoughby and Tosey, 2007). Additionally, more research is needed to study the relationship between organizational learning through the use of Appreciative Inquiry strategies (Day et al., 2012; Buchanan, 2014, Couch, 2017).

\section{Materials and Methods}

The study used exploratory qualitative research design to assess the impact of AIA intervention on human resource capacity. Seven local government authorities participated in this study, these councils are Urban Municipal Council, West B Municipal council, North A District Council, Central District Council, Chake Chake Town Council, Mkoani Town Council and Micheweni District Council.

Purposive sampling technique was used to select fifteen respondents who participated in AI intervention which was conducted by the researcher to seven selected local government councils in Zanzibar, for detailed of this intervention refer to Wakif et al., (2018). The respondents who were purposively selected were asked to describe how they have been able to incorporate the concepts introduced at the AI training as they performed their duties. All participants were able to share multiple experiences during the two months following the workshop where they were able to practice the concepts learned during the workshop, with a positive result in all cases.

\section{Findings of the Study}

The results are structured around a number of key themes that emerged from the literature review, data analysis and interview guided questions. These key categories are:- 


\subsection{Positive AI Experience}

This describes the experience of respondents toward AI intervention, how, in the view of participants of this study, AI differs from other capacity building tools at local government context, how their participation in AI intervention brought change in their organization and the implications of AI principles and stages in bringing transformations in the local government context.

\subsection{Perception of AI in Building Human Resource Capacity at Local Government Context}

This aspect explores how in the perception of the respondents AI enhanced human capacity at local government context in Zanzibar and which factors needs to be in place for AIA to have lasting effect at local context.

\subsection{Interviewee Demographic}

Each participant completed a demographic profile. The age of the 15 participants ranged from 23 to 50. Most participants had a minimum of a Diploma level, 4 had earned a Bachelor's degree, 2 possessed a Master's degree. Table 1.2 lists each participant by professional background, position and the types of Appreciative Inquiry training sessions attended. The selected respondents consisted of 9 female participants and 6 male participants as shown in table 1.2.

\subsection{Qualitative Interview Protocol}

Each interview was conducted following a seven -question protocol. The first three questions collected information on the respondent's experience, lessons learned and sharing of their positive stories after participating in AI intervention training. Question four provided the importance of adherence with AI principles and stages in enhancing human resource capacity. Question five explored the perceptions of respondents towards AI as human resource capacity building tool. Questions six asked about possible challenges and critiques of AI in local government context. The final question gave the subjects the opportunity to share anything that they felt the researcher missed in the interview. The thematic analysis was used to analyze the data and an overview of themes that emerged during the analysis of interview data, the reporting in the following section is organized according to these themes.

\subsection{Positive Engagement with AI Activities}

All interviewees were happy and enjoyed the AI intervention session which practically engaged them into various appreciative activities including peer interviews, individual interviews, discovering and dreaming sessions among others. Most participants explained that it was their first time to be involved in this type of intervention but it was really fun and the quotations showed that, perception of respondents towards AI intervention is positive.

One participant (R005) claimed that "In fact it was very good, very funny, even-though at first I was really shocked to express the positive moments hahaha you know ..........." Another respondent (R012) argued that "Well it was a bit of excitement being involved and the activities for two days were fantastic with a lot of fun." R003 supported that "I experience a lot of personal joy from engaging with AI training, it's a positive experience."

\subsection{Sharing of Positive Stories}

Most of the respondents were concerned about the process of AI which is sharing the positive stories. Some of the respondents giving their views and appreciated the sharing of positive stories even though some of them were nervous at first. Respondent 10 had this to say "I feel appreciated and happy, to share my positive stories to other, even though at first it was very weird". Other argued that, I was so nervous and surprised yeah Allah ......, but after few minutes I cope with the environment.

In a supportive way to which had said by others, some of the respondents clarified that, this process encouraged to share their vision and dreams as commented here "Sharing positive stories, sharing our visions and discussing various issues, I really appreciated it madam." "The experience of sharing with others really opened up my line of thinking." "Reflecting on what was successful was life-giving and reminded me that, I do have some contribution to my organization."

\subsection{AI and Existing Capacity Building Tools Are Differed}

In all interview sessions, participants strongly argued that, there are immense differences between Appreciative Inquiry and their existing capacity building tools. Most of the respondents mentioned the stages of conducting AI training were different compared to their common training tools that were mostly used in building their capacity. "In many trainings that I attended, it was only lecturer who talked most of the time, we became listeners, which is different with AI as you said in that workshop, everyone is a teacher and everyone is a student." Some respondents mentioned positivity on the nature of AI training as quoted here "In most seminar that I attended we start to discuss the problems ............., but in this training I was surprised we started with positive stories".

Also, from the informants narrated their experiences on the differences that they observed. Some respondents explained the similarities that existed between the AI training and existing capacity building tools. They reported that, AI was different from their previous experiences of professional learning and campus change initiatives which had been very negative. In-fact most of the respondents had not experienced any similar AI process before either at local government councils or any other organizations as claimed by R015." I have never noticed this way of working before. It is very good not to focus on what is wrong in the councils but to focus on solutions and what is already good". 


\subsection{Positive Perception of AI Process}

In all of the interview responses, participants strongly supported the AI process in various issues. So, this category was divided into four themes which are positive attitude and empowerment, positive engagement and confidence, applicability in private life and visioning on innovation and creativity.

\subsection{Positive Attitude and Empowerment}

The respondents mentioned the positive attitude as one among personal changes that AI training induced to them. They mean that, they are now focusing at problems in different ways and appreciate the strength of the peers and their councils. "To tell you the truth, people nowadays change and try to express their feelings in polite language, even though it is a problem but the way they express is different as they used to express". R004 commented. "Generally, I see more possibilities and opportunities now than I did before, I am free to express my ideas and when I make a decision now, I consider different angles before to jumping on a conclusion". R001 expressed.

R007 commented "AI changes our way of thinking now madam, we become open minded, for-example, in the morning-call the colleagues, share their ideas and positive thoughts. Now-days, we even believe we that, language is a tool for change." Additional comment was "AI has made our council more positive. It has changed our way of confronting problems, starting to find opportunities and changed our way of talking to each other"

The aspect of empowerment was perceived quite positively as R001 reflects, "absolutely excited and I felt really energized, motivated and feel appreciated.... but I will also love if next time you will include our boss." R011 says, "there was also a big shift around the empowerment of staff ... I think initially it empowered. R0012 commented that, "It was a great opportunity to share and I was looking forward to seeing what would come out of it."

\subsection{Positive Engagement and Confidence}

Many respondents mentioned that their engagement and collaboration with other employee's confidence has increased after implementing AI in their local government. Most respondents mentioned that, AI is experienced not to exclude anyone and it encourages, everyone to participate in decision and work better together. They also observed that, $\mathrm{AI}$ is also said to make it easier for conversations to open up. For example, during weekly meetings. The citations below elaborated more: -

"We are less hierarchical now when working with AI and we are trying to involve more people in for example decision-making, good example was Mwenge day, all employees from top level to lower level, we planned and implemented our day together, ........ It was really fantastic" Commented by administrative officer

"AI has made us work more together in teams. The strength of working together in teams becomes much greater as you involve everyone in a different way. For-example we had prepared our Mwenge day by giving each group their tasks, and for the first time in collaboration with our Director of the council, we managed to perform wonders" R011.

The respondents also appreciated the AI and commented that it enhanced their confidence, R007 said that "........... this training helped me and my colleague to be more confident.

"You cannot believe, people now-days dare to speak and contributed, some of the staff for the first time have dared to present their ideas and some of them have been quite outstanding." R002

"I understand myself, I become more confident, innovative and have creative ideas and I feel appreciated. I also talk to my supervisor in a positive way." R010.

\subsection{Applicability in Personal Life}

Some Respondents mentioned that, AI become a part of their daily life and if you once accept AI, it will never go away. They argued that, AI eventually affects their fundamental behavior and they can not only use at work but they apply it also in their private life. Some respondents also mentioned that, they have practiced AI on their children. As elaborated by R009 that, "AI is the only method this far that has not only affected my work life, but also the way I am with my family". As supported by R005 "I use AI's principles and steps in my private life when I raise my children and even when we are talking with my husband. In fact, it induces something positive and gives results very quickly."

Another respondent (R010) added that "training changes my personal attitude in performing my daily life activities in general, now I started to forget most of my negative feelings with my relatives. As you know negative feeling reduce the life span....... Also, it encourages me to work independently because of appreciation mind that I have."

\subsection{Enhancing Positive Knowledge and Skills}

All the interviewee participants shared their perception towards knowledge and skills improvement after AI intervention. They explained that, AI improve their skills, innovation and creativity. They observed that AI encourage them to have dreams and visions, nowadays they look back on successful experiences from the past and dream about how they can use these in the future.

Some respondents consider AI to be more future-oriented and more positive than previous ways of working. "It is very nice, it boosts my knowledge on performing my tasks and brings changes in our office, now-days most of us we are doing our duties without tight supervision."

"Build my knowledge and encourage to have dreams which I did not have before training. For me, it was only "come to the office and doing my daily activities, I didn't have any dream toward my office. I also tried to change my colleagues. We also started to use stages of AIA in making decision". Commented by R008. "It is innovative tool for change, encourage us to vision what we want to achieve, not what we want to avoid." R001 


\subsection{Building Positive Organizational Changes}

The findings of the interview sessions elaborated that, AI did not only bring impact to local government employees but also to their local government authorities in general. Even though it was only two months since introduction of AI at local government level. The researcher was had wondering if it would provide any useable impact to the councils. Remarkably, the respondents experienced that, great changes had happened during this short period of time. The respondents argued that, biggest impact of AI in local government council is perceived to be in the customer service area. Respondents stated that, "it had a significant impact on us, lifting our overall customer service and outperforming in some cases simply because it motivated people."

The respondents observed that, "We change in customer care and provision of services. It changes the way that customers are handled now, customers are happy with our services." They started to appreciate".

"I think the whole institution has been affected by AI. Everyone knows about AI. From my perspective, I can see that my subordinates have been affected as we put emphasis on the best at the meetings. We talk a lot about the best results and things like that"

"We also dream to be municipal few years to come after the training we are more committed to achieve this dream and we even started to share positive stories for those who are at Municipal before and other councils who are now transferred to Chake Council".

"We appreciate the AI training and we believe that if the local government management will give us support, we will achieve what we dream in AI training which is Appreciative Decentralization by $2020 . "$

\section{Discussion}

In all interview sessions, respondents reported that they experienced AI to be positive and that, AI creates energy and positive feelings. The respondents said that they feel more positive and feel appreciated because of the positive sharing of their stories which took place during AI interventions. Similar findings were reported in previous studies on experience of AI that respondents from various fields including nurses, non-governmental organizations staff and even private sectors. According to Chauke, (2014), respondents in her study experienced positive emotions of joy, pride, enthusiasm and excitement because of the positive conversations. Hung et al., 2018 added that, AI make life easy and fun, some of the respondents even claimed that, "It's so nice to see everyone is having so much fun. We should have more of this kind of event."

The study conducted by Bengsstoon and Rokka (2011) identified that, AI is experienced to create positive emotions and a change towards a positive mindset, as the employees learn to see possibilities instead of problems. Similar findings were observed by Fified (2013) in his study "How Might Appreciative School Leadership Meet the Needs of 21st Century Schools? An Initial Inquiry" and observed that participants who participated in team learning, AI intervention reported feeling empowered and energized with a new sense of purpose and dedication. It was emphasized by one participant that, "I think it was not only just being a community; it was just giving, each one of us, a sense of pride and discovering things that you probably don't feel comfortable doing but then you try and you do it!"

This concluded that, by experience AI as positive, it seems that the positive emotions towards AI indicate that personal goals can be reached. This is also congruent with a methodological literature review of the AI studies such as Trajkovski et al., (2013) that found how 'AI was mostly positively perceived by participant."

The respondents also observed that, there were differences between AI activities and other problem-solving methods. The respondents mentioned they have never experienced a similar way of going through capacity building activities before. They meant that, when they were using traditional methods on change, they were focusing on weaknesses, searching for faults and who to blame. This finding supports literature that, AI assures that, when using AI, the organization puts emphasis on what the employees are doing right Cummings and Worley (2001) and also aligns with the AI principle. Couch 2017 added that, most participants reported the same positive approach to problem solving as one of the lasting benefits of using Appreciative Inquiry. The study of Bellinger and Elliott, 2011 cited in Cojocaru and Bragaru, (2012) also in line with this and reported that, AI leaves problems behind in favour of positive experiences, in order to obtain a change in the desired direction. This implies that, Appreciative Inquiry is an effective capacity building approach which encourage positive changes as observed by Cooperrider and Whitney, 2008.

The qualitative findings also demonstrated that, most of the respondents perceived AI as a positive method for capacity building. The respondents agreed that, engaged in AI intervention improved their individual and council's performance because of collaboration, innovation and creativity. This also enabled the council specifically Chake Chake Town Council to create shared images of Appreciative Decentralization as their preferred future based on their positive core. Reflecting back on the results of interviews, most of the respondents mentioned that, positive attitude as one among personal changes that AI training induced to them. This means that they are now focusing at problems in different ways and appreciate the strength of the peers and their councils. Previous studies have provided adequate evidence of a positive relationship between Appreciative Inquiry and empowerment and attitude (Thibodeau, 2013; Aronson, 2010, Chapagain, 2004).

Similar findings were reported in Thibodeau, (2013) study "Appreciative Accreditation." The respondents who participated in the quasi experimental research, reported individual changes through interview session and commented that "I find that I tend to explain things to more people and to try to bring them on-board and I also try to share the bigger picture of the vision."

The results also describe that, employees were fully positively engaged as explained by respondents in their interviews. This result is consistent with various other studies such as Chapagain and Ojha, 2008; Saretsky, 2013; Chauke, 2014; Coates, 2017. 
Chapagain and Ojha (2008) point out that, qualified and experienced professionals of AI who are familiar with Appreciative Inquiry approach experienced that, Appreciative Inquiry increases AI practitioner's confidence through skill enhancement in partnering, negotiations and contributing to the empowerment and overall leadership. The study also revealed that, AI improved positive team and collaboration which are in line with this study.

This finding also supports Ludema et al., (2003) assertion that paired interviews allow each participant to establish a deep appreciative relationship with at least one another person in the group. In addition, small groups build a sense of community through the process of discovering the positive core (Cooperrider \& Whitney 2005)

Barrett and Fry (2005), who supported this idea argued that, active participation in an Appreciative Inquiry generates more hope and confidence in building human capacity and is a principal benefit from participating in an Appreciative Inquiry.

The unique findings that was observed in this study is that, respondents of this study agreed that AI is not a unique strategy which enhanced participants to apply in their private life. This result is consistent with Bengtsson and Rokka, 2012 who experienced elaborated that "People who have been working with AI, also choose to live AI in their private lives. AI is a contrast to the western world's surrounding environment, which is characterized by criticism." In the same study, the authors acknowledge that, "We perceive that the desire to live AI is a result of the search for something that is not criticizing."

This findings agreed with Fified (2013) who concluded that, AI served not only as a methodology but also as a framework for allowing participants to discover their positive core and to examine possibilities for building upon that to develop their own and the institution's capacity as Cooperrider and Whitney (2005) recognized that AI may be used as an action research framework and methodology to promote a co-evolutionary search for the best in people, their organization and the world around them. This idea was also emphasized by Hung et al., 2018 who believe that, talking about and listening to the stories connected people and built relationships.

All the interviewee participants shared their perception towards knowledge and skills improvement after AI intervention. They explained that, AI improve their skills, innovation and creativity. They observed that, AI encourage them to have dreams and vision, nowadays they look back on successful experiences from the past and dream about how they can use these in the future. This finding aligned with previous studies that Appreciative Inquiry improved capacity of the employees as observed by Hung et.al, 2018; Chapagain and Ojha, 2008; Day et.al., 2012; Jansen, 2014. Hung et al., 2018 in their current study which is consistent with these findings demonstrated that, this study supports that appreciative inquiry is a useful strategy for bringing the practitioners together to develop knowledge and take action for practice change.

\section{Conclusion}

The application of the Appreciative Inquiry framework as a tool to build employees skills, attitude, knowledge and collaboration appeared to be successful in this research study. Through the detailed examination of the experiences documented by the participants, it is clear that the framework has not only made a positive impact on employees, but it also has the potential to extend into improvements of local government authorities.

\section{Acknowledgements}

The authors would like to express words of appreciation and thanks to Zanzibar University for funding this research through a PhD sponsorship of the first author.

\section{References}

i. Aronson N. A. (2012), A study of the Effects of Appreciative Inquiry on teachers 'classroom practice. A thesis for the Award of Doctor of Philosophy in Education Leadership.

ii. Barrett, F. and Fry R. (2005). Appreciative Inquiry: A Positive Approach to Cooperative Capacity Building. Chagrin Falls, OH: Taos Institute Publishing.

iii. Buchanan, Pamela. (2014), A path to change in Education. A thesis for the Award of Doctor of Philosophy in Education Leadership.

iv. Bechtold, Mark (2011), Improving Worker Morale through the use of Appreciative Inquiry, Industrial and Commercial Training, Vol. 43 No. 1 pp 25- 30

v. Calabrese, R. (2015). A collaboration of school administrators and a university faculty to advance school administrator practices using Appreciative Inquiry. International Journal of Educational Management, 29(2), 213221

vi. Calabrese, R., Hester, M., Friesen, S., \& Burkhalter, K. (2010). Using appreciative inquiry to create a sustainable rural school district and community. International Journal of Educational Management, 24(3), 250-265.

vii. Carter Michelle T (2009) Appreciative Inquiry and Adult Transformative Learning as An Integrated Framework to Guide Life Coaching Practice. A thesis for the Award of Doctor of Philosophy.

viii. Chapagain, C.P and Ojha, G. P. (2008). Appreciative Inquiry for Enhancing Individual and Organization Capacity. Revista de cercetare [interven] ie social. Vol. 20, pp. 7-18

ix. Chauke, Motshedisi (2014) Transforming student nurse's image of nursing: An Appreciative Inquiry Approach. A thesis for the Award of Doctor of Literature and Philosophy in Health

x. Coates, L. (2017) Exploring narratives of success in learning in a Key Stage Three Pupil Referral Unit: An Appreciative Inquiry through a Dialogic Narrative Lens. A thesis for the Award of Doctor of Philosophy in Education 
xi. Cooperrider, D.L. and Whitney, D. (2005), Appreciative Inquiry: A Positive Revolution in Change, Berrett-Koehler Publishers, San Francisco, CA.

xii. Cummings, T. and Worley, C. (2001) Organization Development and Change (7th ed.) Minneapolis: West Publishing Company.

xiii. Day, W.J., and Holladay C.L. (2012), Appreciative Inquiry: An Effective Training Alternative to Traditional Adult Learning? Journal of Psychology 2012. Vol.3, No.12A, 1125-113

xiv. Heiser E. John and Swallow K. Jeffrey (2015) Magnetrol International, Incorporated: A Case Study in the Use of Appreciative Inquiry South Asian Journal of Business and Management Cases 4(1) 27-39

xv. Howard, V. (2013). Expanding the Application of Appreciative Inquiry Based on Its Principles of Human Systems. The Qualitative Report, 18(17), 1-5.

xvi. Hung, L; Phinney, A. Chaudhury, H. Rodney, P., Tabamo, J. and Bohl, D. (2018): Appreciative Inquiry: Bridging Research and Practice in a Hospital Setting International Journal of Qualitative Methods Volume 17: 1-10

xvii. Jansen, C. (2014) Leadership development through appreciative inquiry: complexity thinking in the nongovernment (NGO) sector of Doctor of Philosophy in Education

xviii. Lehner R, Hight D.L. (2006). Appreciative inquiry and student affairs: A positive approach to change. College Student Affairs Journal, 25(2): 141-151

xix. Ludema, J., Whitney, D., Mohr, B \& Griffin, T. (2003). The appreciative inquiry summit: a practitioner's guide for leading large group change. San Fransisco, CA: Berret Koehler

xx. Mohammed, M.; Haji, A.; Yussuf, R. and Mohammed, A. (2011). The Assessment of Capacity, Training Needs and Developing Training Program at Local Government Authorities in Zanzibar. A report submitted to President Office, Regional Administration, Local Government and Special Departments

xxi. Ratanaphunsri, Achara (2014). The Impact of an Appreciative Inquiry Organization development intervention on Appreciative learning organization: A case study based on a private IT solution Provider in Thailand

xxii. Schooley, S.E. (2012) Using Appreciative Inquiry to Engage the Citizenry: Four Potential Challenges for Public Administrators, International Journal of Public Administration, 35:5, 340-351

xxiii. Saretsky, K. Lynn (2013) Appreciative Inquiry for Strategic Planning: An Evaluative and Exploratory Case Study of Two Colleges

xxiv. Stellnberger Martin (2010) Evaluation of Appreciative Inquiry Interventions: A thesis submitted to the Victoria University of Wellington.

xxv. Thibodeau, John (2011), "Appreciative Accreditation: A Mixed Methods Explanatory Study of Appreciative Inquiry-Based Institutional Effectiveness Results in Higher Education". (Doctoral dissertation). Retrieved from ProQuest Dissertations and Theses database. (AAT 3228078) 